\title{
ENVIRONMENTAL AWARENESS IN DIFFERENT EUROPEAN CULTURES
}

\author{
Zsuzsanna Bacsi* \\ University of Pannonia, Georgikon Faculty, Keszthely, Hungary
}

The 28 countries of the European Union represent a rather heterogeneous group regarding their geography, history, and national cultures. Their response to the current global challenges depends on their way of viewing the world, and that is largely influenced by their national values and beliefs. The research compares the environmental awareness in distinct country groups and identifies the components of national culture, which, by their different approaches to the environmental sustainability, influence the most. The time span of the analysis is seven years from 2012 to 2018. National culture is defined by Hofstede's cultural dimensions, and the environmental awareness data were collected from the Eurobarometer surveys of the EU. The main findings show that the environmental awareness in the EU increases with time and is higher in indulgent, more individualistic, and more long-term oriented countries, while the level of masculinity and uncertainty avoidance or power distance did not matter. The Scandinavian countries are remarkably environmentally aware, while the other groups of countries do not differ in this respect.

Keywords: environmental awareness; Hofstede's cultural dimensions; The European Union, Eurobarometer survey

The 28 countries of the European Union (of 2018) differ in many respects, including geography, climate, history, economic development and national cultures. In spite of their differences, they have to find suitable responses to the current global challenges, including the environmental sustainability, economic inequalities and poverty, terrorism and cultural conflicts. Although the EU tries to outline harmonised actions in response to these challenges, the individual countries may react differently, depending on their way of viewing the world. National culture, i.e. the system of values and beliefs, and its impact on the success of the countries in the global economy has been an important research topic. Many approaches are known to capture and measure various aspects of culture, the most famous of them being Hofstede's system of six cultural dimensions. The present study applies these dimensions to specify the cultural traits of the 28 EU member states (as of 2018, including the UK) and classifies these countries into four cultural groups, based on geography and history: Former Socialist, Scandinavian, Mediterranean, and Other Western countries.

The research compares the environmental awareness in these distinct country groups and looks for components of national culture that influence their different approaches to the environmental sustainability the most. The environmental awareness data were collected from the Eurobarometer surveys of the EU from 2012 to 2018, and statistical analyses were carried out to assess the relationships of culture and environmental concerns.

The European Union in its Eurobarometer survey series regularly asks its citizens about the most serious issues they think their countries would have to face in near future (EC, 2012-2019). As the surveys have revealed, climate and environment are among the main concerns of the European citizens. These were chosen from a list containing immigration, terrorism, public finances, economic situation, climate change, unemployment, the EU's influence in the world, rising prices, inflation or cost of living, environment, crime, pensions, energy supply and taxation. The respondents were asked to choose the two most important issues. Survey data indicate increasing awareness of the environment, climate change and energy issues. These were mentioned as the most important by $19.7 \%$ of the population in 2019 , which is a considerable increase from the $5.2 \%$ value of 2013 . However, people's awareness of the environmental problems depends on the general cultural traits, beliefs and values of the population. It is a well-known fact that the inherent values and beliefs of people determine the way how they view the surrounding world. Therefore, it is reasonable to assume that the basic national cultural values will have an impact on the environmental awareness and the resulting activity patterns experienced in any country (Gould et al., 2018; Halkos and Tzeremes, 2013).

National cultural features can be measured by a variety of dimensions. One of the most widely used ones is that of Hofstede $(1980,2010)$. Although Hofstede established his system of cultural dimensions relying on the survey data about the IMB employees' work-related values, and hence gave way to serious criticism regarding the general applicability of his cultural setup, his dimensions have been validated by new surveys done many times and under many different circumstances (see Hofstede et al., 2010, p. 35). The original Hofstede dimensions included individualism-collectivism, power distance, masculinity-femininity, and uncertainty avoidance. Later, two new dimensions as are a long vs. short-term orientation and indulgence vs. restraint were added to the model, and in the 2000s, research based on the data from the World Values Survey (Minkov, 2007) resulted in a new calculation of these dimensions (Hofstede et al., 2010). Although many other concepts have been evolved (see Kaasa et al., 2016 for a detailed literature review), the so-called Hofstede dimensions are considered a grounded approach for describing culture and have been widely used in analysing the cross-country cultural differences (Kaasa et al., 2016). Country-wise, the dimensions are published on a website (Hofstede Insights, 2016).

The six cultural dimensions by Hofstede are (Hofstede, 2011):

1. Power Distance, related to the acceptance of the basic problem of human inequality by the less powerful members of a society.

2. Uncertainty Avoidance, related to the level of stress in a society from the unknown future.

3. Individualism versus Collectivism, related to the integration of individuals into primary groups.

4. Masculinity versus Femininity, related to the division of the emotional roles between women and men. 
5. Long-term versus Short-term Orientation, related to the choice of focus concerning the people's efforts: the future or the present and past.

6. Indulgence versus Restraint, related to the gratification versus control of the basic human desires connected with life enjoyment.

Although these dimensions are relatively independent of each other, capturing different aspects of human beliefs and behaviours, their relationship to each other and to the economic performance level of the countries have all been analysed. It is a well-established fact, that GDP per capita is correlated with the Power distance (negatively) and with the Individualism (positively). Therefore, when working with the Hofstede cultural dimensions, the GDP levels have to be included in the analyses. Hofstede (1980) found out that GNP per capita is in a significant positive correlation with individualism and in a significant negative correlation with power distance, while it is not correlated with uncertainty avoidance or masculinity. Directions of these correlations were found later to depend on the magnitudes of the various cultural dimensions (Cox et al., 2011).

Hofstede's cultural values country-wise have been used to classify the European countries by their cultural traits into five main groups: Nordic countries, Latin, Germanic, Anglo-Saxon, Eastern Europe (Cimpeanu et al., 2013). These cultural traits and differences among the country groups are subject to evaluation from many aspects, including temporal changes, cultural convergence and divergence. The unifying impact of the $\mathrm{EU}$ is notable in the cultural dimensions of the member states due to the increased institutional harmonisation, which leads to a cultural convergence, while the non-EU countries in Europe (like Norway) tend to diverge from the EU average values, (Gooderham and Nordhaug, 2002).

The five country groups differ in several aspects and the reasons for these differences are associated with geographic and climatic differences as well as political systems, history, wars and political leadership. For example, differences of the German and the Anglo-Saxon groups exist; Britons maintain the monarchy, whereas Germans have rejected socialism and autocracy, even despite the fact that these political systems are popular in their neighbouring countries. Regarding similarities, German and English culture lends itself to a progressive economic development, while Portuguese and Spanish culture does not (Tabellini, 2010). Nordic countries, including Sweden and Finland, have developed cultures based on a similar economic history and religion, and all share a similarly low value in Hofstede's masculinity/femininity category, while the less affluent Eastern European countries possess high masculinity index values (Barkley and Eggertsson, 2017).

Except the cross-national cultural differences, the within-country differences are also important. The research results have identified countries where the within-country cultural variability is larger (Spain, Portugal, France) and smaller (Finland, Sweden, Norway) than the cross-national variability. While one or more regions of a country are remarkably distinct within one or two dimensions, there are no signs of regional differences within the other dimensions. This outcome has an important consequence: it is not easy to group regions according to culture (Kaasa et al., 2014) and this may be true also on a cross-national level.

Except the Hofstede's survey-based cultural dimensions, other attempts have also been made to create country clusters based on cultural similarities and differences. One of the most famous ones is the 'Global Leadership and Organizational Behaviour Effectiveness' (GLOBE) Research Program (House et al., 2004), based on data from 62 countries. The GLOBE clusters were made by the following cultural dimensions:
1. racial/ethnic distribution;

2. religious distribution;

3. geographic proximity of the countries;

4. major language distribution;

5. colonial heritage (Mensah and Chen, 2013).

Altogether, 10 major clusters were established: Anglo, Latin Europe, Nordic Europe, Germanic Europe, Eastern Europe, Latin America, Middle East, Sub-Saharan Africa, Southern Asia, and Confucian Asia (House et al., 2004).

Cultural characteristics influence all the aspects of economic and social life, but various cultural dimensions have different types of effects: the level of innovation performance, for example, is positively impacted by indulgence and individualism, while power distance and uncertainty avoidance are negatively related to a national innovation performance (Andrijauskiene and Dumciuviene, 2017). Although the cultural dimensions may be less important than the economic determinants, they may be more significant than the political, legal and ecological ones (Andrijauskiene and Dumciuviene, 2018).

Culture influences not only the economic performance, but also the way people see the surrounding world, including the environment. Cultural index values have been compared to the citizens' relationship to the natural environment to prove that the way the individuals relate to the natural environment is culturally patterned. Research shows that thinking about future, together with a self-transcendent orientation and psychological distance are all in association with the pro-environmental attitudes and behaviour, and there is evidence that an overwhelming majority of the world's population supports the environmental protection (Milfont and Schultz, 2016). Concerning the analysis of the factors influencing the pro-environmental behaviour, the geographic location of a study, age of participants and the percentage of females in a study were not significant. The lack of importance of the geographic location as an influencing factor contradicted the cross-cultural studies, which report that the way the individuals relate to the natural environment is culturally patterned (Milfont and Schultz 2016). This might have happened because the research has focused on the urban populations in the Western countries. Nature connectedness needs to be investigated in the non-Western cultures (Whitburn et al., 2020).

Recent generations tend to be more concerned about the environment. Both environmental education and science literacy are found to correlate with the climate change risk perception positively, meaning that the individuals, who are more adept at interpreting the scientific and environmental literature, are more likely to see the climate change as a problem (Medina et al., 2019).

A survey conducted in Hungary found out that the direct impact of Hofstede's cultural dimensions on the pro-environmental behaviour was not significant. The findings indicate that only individualism and power distance have a significant, but negative impact on the pro-environmental behaviour (Nagy and Konyha, 2018). Although this result seems to contradict the former results, this survey focused only on one country. The researchers have also concluded that in collectivist societies with low power distance, the probability of the pro-environmental behaviour is higher.

Cho et al. (2013) investigated the relationship between the collectivism vs. individualism, cultural dimension and environmentally conscious behaviour, and found out that both collectivism and individualism are important influential factors contributing to higher levels of environmentally conscious commitment. 
Table 1 Variables and data sources

\begin{tabular}{|c|c|c|}
\hline Variable name & Variable meaning & Data source \\
\hline GDP_per_cap & GDP per capita, constant 2010 price levels (EUR) & Eurostat, 2019b \\
\hline ENAW & $\begin{array}{l}\text { \% of population considering the environment, climate and } \\
\text { energy issues to be the major issues for the country }\end{array}$ & EC, 2012-2019 \\
\hline & Hofstede cultural index values, 2015 & Hofstede Insights, 2016 \\
\hline PDI & \multicolumn{2}{|l|}{$\begin{array}{l}\text { Power distance index: } \\
\quad \text { large value: hierarchical order; low value: people equalize }\end{array}$} \\
\hline INDI & \multicolumn{2}{|l|}{$\begin{array}{l}\text { individualism or collectivism index: } \\
\text { large value: individualistic; low value: collectivist }\end{array}$} \\
\hline MAS & \multicolumn{2}{|l|}{$\begin{array}{l}\text { Masculinity or femininity index: } \\
\text { large value: masculine; low value: feminine }\end{array}$} \\
\hline UNA & \multicolumn{2}{|c|}{$\begin{array}{l}\text { Uncertainty avoidance index: } \\
\text { large: unhappy about uncertainty, intolerant; low: tolerates uncertainty well }\end{array}$} \\
\hline LTO & \multicolumn{2}{|c|}{$\begin{array}{l}\text { Index of long-term or short-term normative orientation links with the past: } \\
\text { large: pragmatic, accepts change, prepares with education; } \\
\text { low: prefers to live by traditions, suspicious of change }\end{array}$} \\
\hline INDG & \multicolumn{2}{|c|}{$\begin{array}{l}\text { Indulgence vs. restraint index: } \\
\text { large: indulgence; low: represses indulgence, lives with strict constraints }\end{array}$} \\
\hline
\end{tabular}

\section{Material and methods}

\section{Measuring the environmental awareness}

The environmental awareness of the population was measured by survey response percentages. The EU citizens were asked in Eurobarometer surveys to choose the two major problems for their countries in near future. The list contained problems related to the environment, climate and energy, and the percentage of people choosing such problems was used as an indicator for environmental awareness.

National cultural traits were measured by Hofstede's six cultural dimensions, which are available for many countries from 2015. The analysis was based on the secondary data sources, as listed in Table 1.

\section{Country grouping}

The countries were classified by their geographical regions as Scandinavian (SC), Former Socialist (FS), Mediterranean (ME), and Other Western (OW) countries. These country groups were then compared by their environmental awareness level, national income, domestic camping tourism indicators, and cultural characteristics according to the Hofstede's six cultural dimensions:

$\square$ The Scandinavian country group includes 3 countries: Denmark, Finland and Sweden.

$\square$ The Mediterranean country group consists of 6 countries: Greece, Portugal, Spain, Italy, Malta and Cyprus.

$\square$ The Other Western country group contains 8 countries: Belgium, Germany, Ireland,
France, Luxembourg, the Netherlands, Austria, and the United Kingdom.

$\square$ The largest country group is that of the Former Socialist countries, consisting of 11 countries: Bulgaria, the Czech Republic, Estonia, Croatia, Latvia, Lithuania, Hungary, Poland, Romania, Slovakia and Slovenia.

This grouping is similar to the country classifications described by the literature (Barkley and Eggertsson, 2017; Cimpeanu et al., 2013; Tabellini, 2010). Our sample merged the Anglo and Germanic countries with the group of the 'Other Western countries'. The reason for this was the fact that only Britain and perhaps Ireland can be considered to have purely Anglo-Saxon culture, country groups

Source: author's own research and these two would give a very small sample. Many of the Western European countries represent a mixture of the Anglo-Saxon and Germanic characteristics. Therefore, merging them into one group seemed as a reasonable choice.

\section{Statistical analyses}

Annual data for 2012-2018 were used for 28 member states of the EU (including the United Kingdom). Although the data for the Hofstede's cultural dimensions referred to only one year, 2015, they could be safely used for the full sevenyear time period of the research, as cultural traits change very slowly. Data were analysed by descriptive statistics, correlation analysis and multiple regression analysis, using SPSS V22.0, and Microsoft Office Excel 2013.

\section{Results and discussion}

Characteristics of the 4 country groups are compared in table 2, giving the results of a descriptive analysis for the environmental awareness and the dimensions of the national culture.

As the CV\% values show, the country grouping is a rather good distinction of the $28 \mathrm{EU}$ countries, because regarding GDP_per_capita, LTO and INDG, the relative standard deviations (CV\%) within the group are smaller in all of the four groups and regarding ENAW and PDlin, in at least three of the four groups, rather than in the whole set of countries. INDI, MAS and UNA are more varied among the country groups. Country groups differ considerably by their cultural traits, as well as by their environmental awareness and per capita income levels, as is demonstrated by figure 1.

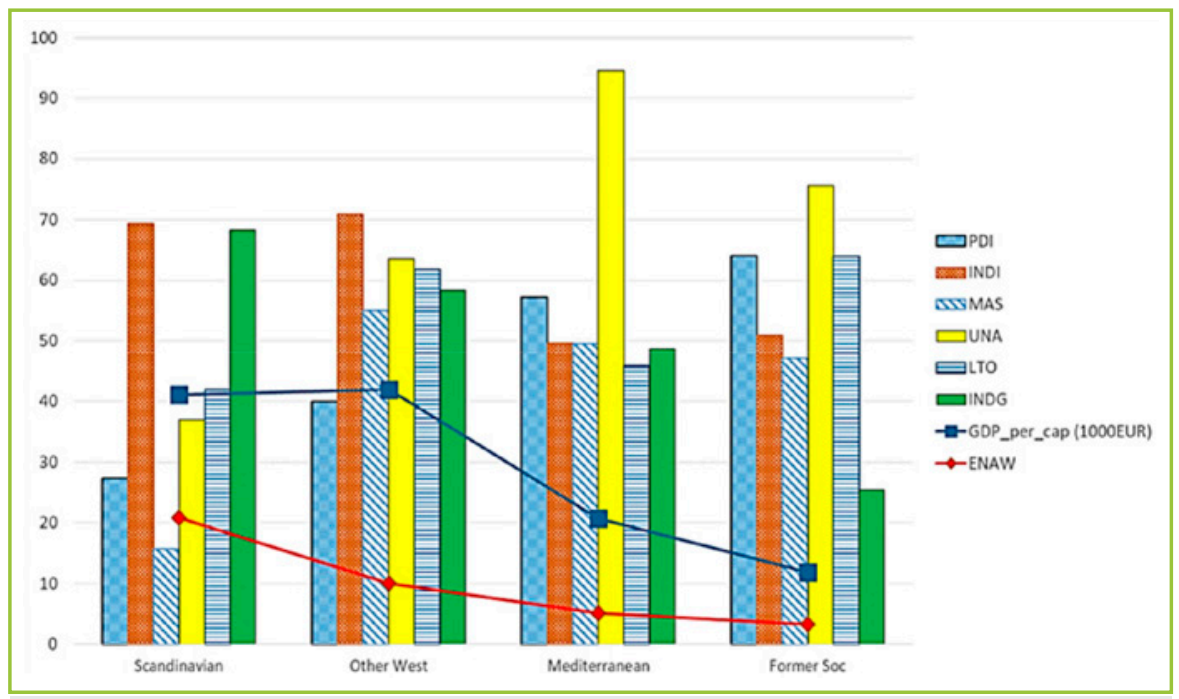

Figure 1 Hofstede dimensions (2015), environmental awareness and GDP (2012-2018 average) by 
Table 2 Descriptive statistics for variables by a country group

\begin{tabular}{|c|c|c|c|c|c|c|c|c|c|}
\hline Country group & indicator & ENAW & GDP_per_cap & PDI & INDI & MAS & UNA & LTO & INDG \\
\hline \multirow{4}{*}{ Scandinavian } & AVG & 20.84 & 41084.8 & 27.33 & 69.33 & 15.67 & 37.00 & 41.98 & 68.23 \\
\hline & St.dev & 9.45 & 4671.2 & 6.81 & 4.76 & 8.79 & 16.14 & 8.05 & 8.56 \\
\hline & $\min$ & 6.83 & 34390.0 & 18.00 & 63.00 & 5.00 & 23.00 & 34.76 & 57.37 \\
\hline & $\max$ & 38.77 & 48260.0 & 33.00 & 74.00 & 26.00 & 59.00 & 52.90 & 77.68 \\
\hline \multirow{5}{*}{ Other western } & AVG & 10.08 & 41930.4 & 40.00 & 70.88 & 55.00 & 63.50 & 61.90 & 58.29 \\
\hline & St.dev & 7.42 & 15786.4 & 17.65 & 10.18 & 19.01 & 20.36 & 17.45 & 9.62 \\
\hline & $\min$ & 0.68 & 30200.0 & 11.00 & 55.00 & 14.00 & 35.00 & 24.43 & 40.40 \\
\hline & $\max$ & 41.07 & 83470.0 & 68.00 & 89.00 & 79.00 & 94.00 & 82.87 & 69.42 \\
\hline & CV\% & $73.6 \%$ & $37.6 \%$ & $44.1 \%$ & $14.4 \%$ & $34.6 \%$ & $32.1 \%$ & $28.2 \%$ & $16.5 \%$ \\
\hline \multirow{5}{*}{ Mediterranean } & AVG & 5.13 & 20683.8 & 57.20 & 49.60 & 49.40 & 94.60 & 45.94 & 48.59 \\
\hline & St.dev & 7.59 & 3512.8 & 4.42 & 17.64 & 13.47 & 13.24 & 10.73 & 15.25 \\
\hline & $\min$ & 0.08 & 16050.0 & 50.00 & 27.00 & 31.00 & 75.00 & 28.21 & 29.69 \\
\hline & $\max$ & 28.10 & 26760.0 & 63.00 & 76.00 & 70.00 & 112.00 & 61.46 & 69.87 \\
\hline & CV\% & $148.0 \%$ & $17.0 \%$ & $7.7 \%$ & $35.6 \%$ & $27.3 \%$ & $14.0 \%$ & $23.4 \%$ & $31.4 \%$ \\
\hline \multirow{5}{*}{ Former Socialist } & AVG & 3.23 & 11914.7 & 64.09 & 50.91 & 47.09 & 75.55 & 63.93 & 25.45 \\
\hline & St.dev & 2.22 & 3519.4 & 19.88 & 17.37 & 29.52 & 13.35 & 13.66 & 9.99 \\
\hline & $\min$ & 0.09 & 5350.0 & 40.00 & 27.00 & 9.00 & 51.00 & 37.78 & 12.95 \\
\hline & $\max$ & 9.27 & 20170.0 & 104.00 & 80.00 & 110.00 & 93.00 & 82.12 & 47.54 \\
\hline & CV\% & $68.7 \%$ & $29.5 \%$ & $31.0 \%$ & $34.1 \%$ & $62.7 \%$ & $17.7 \%$ & $21.4 \%$ & $39.3 \%$ \\
\hline \multirow[t]{3}{*}{ ALL } & $\min$ & 0.08 & 5350.00 & 11.00 & 27.00 & 5.00 & 23.00 & 24.43 & 12.95 \\
\hline & $\max$ & 41.07 & 83470.00 & 104.00 & 89.00 & 110.00 & 112.00 & 82.87 & 77.68 \\
\hline & CV\% & $110.4 \%$ & $63.4 \%$ & $40.4 \%$ & $29.9 \%$ & $54.1 \%$ & $31.7 \%$ & $28.4 \%$ & $44.1 \%$ \\
\hline
\end{tabular}

Note: $\mathrm{CV} \%=$ St.dev/AVG (\%)

Source: author's own research

The main cultural similarities and differences among the country groups include:

$\square$ The Scandinavian countries are similar to the other Western countries regarding individualism and indulgence (both high), power distance (rather low), and in their high GDP levels.

$\square$ The Former socialist and Mediterranean countries are similar in their level of individuality (lower than in the Scandinavian and the other Western group), masculinity (higher than in the Scandinavian, but lower than in the other Western group), and also in their high power distance and uncertainty avoidance.

$\square$ The Mediterranean countries are moderate and the Former socialists are low in indulgence and in the GDP level, while the other two country groups are higher in both.

$\square$ The Scandinavian group is strikingly low in masculinity, while the other three groups are rather similar.

$\square$ The long-term orientation is higher in the Former socialists and other Western countries and lower in the Scandinavian and the Mediterranean countries.

$\square$ Where individualism and indulgence are high, and power distance is low, the environmental awareness is also high, as well as the GDP level.

\section{Correlations between the Hofstede dimensions and the environmental awareness}

As table 3 presents, the country groups considerably differ according to the relationship between their cultural features and their environmental awareness:

$\square$ Looking at the relationship between the GDP level and the environmental awareness, a medium positive correlation coefficient is seen, when considering all countries together. However, when looking at the correlations groupwise, it is clear that this positive correlation occurred due to the Scandinavian countries, and to a lesser extent, due to the Former socialist countries, while this relationship does not exist in the other Western group or in the Mediterranean. In Scandinavia and the Former socialist countries, more income means more environmental awareness, while this pattern does not exist in rest of the countries. This is interesting, because SC has the highest income level, while FS possesses the lowest one.

$\square$ Looking at the relationship between the environmental awareness and the power distance, with all the countries in the sample, a negative correlation is experienced, but looking at the country groups separately, the negative correlation is experienced in $\mathrm{SC}$ and in $\mathrm{ME}$, but to a smaller 
Table 3 Correlation coefficients among the cultural dimensions and the environmental awareness by the country groups

\begin{tabular}{|l|c|c|c|c|c|}
\hline Corr with ENAW & SC & OW & ME & FS & ALL \\
\hline GDP_per_cap & 0.628 & -0.021 & -0.017 & 0.286 & .470 \\
\hline PDI & -0.239 & 0.054 & -0.209 & 0.119 & -.389 \\
\hline INDI & 0.510 & 0.025 & 0.334 & 0.051 & .371 \\
\hline MAS & -0.545 & -0.313 & -0.050 & 0.308 & -.249 \\
\hline UNA & -0.536 & 0.143 & -0.054 & -0.029 & -.403 \\
\hline LTO & 0.305 & 0.393 & 0.100 & 0.037 & -.056 \\
\hline INDG & 0.567 & -0.163 & 0.421 & 0.060 & .534 \\
\hline
\end{tabular}

Source: author's own research

Table 4 Correlation coefficients with the Year variable

\begin{tabular}{|l|c|c|c|c|c|} 
& SC & OW & ME & FS & ALL \\
\hline Corr ENAW - year & 0.614 & 0.602 & 0.260 & 0.610 & 0.342 \\
\hline Corr GDP - year & 0.250 & 0.117 & 0.247 & 0.230 & 0.071 \\
\hline
\end{tabular}

Source: author's own research

extent, while OW and FS show a weak positive correlation. Higher power distance in SC and ME results in smaller environmental awareness, while in $\mathrm{OW}$ and $\mathrm{FS}$ does not. Again, SC possesses the lowest PDI, while ME has nearly the highest value.

$\square$ A very similar pattern emerges with respect to the individualism and indulgence - but with opposite signs. The Scandinavian and the Mediterranean countries have a strong positive correlation among the environmental awareness and these cultural traits, while the relationship is weak in $\mathrm{OW}$ or $\mathrm{FS}$ countries.

$\square$ Uncertainty avoidance is negatively related to the environmental awareness both for the pooled sample of all countries and for the Scandinavian countries, too. However, this relationship does not exist for ME and FS, and a very weak positive relationship is experienced in the other Western countries. The Scandinavian countries with low levels of uncertainty avoidance (i.e. with better tolerance to uncertainty) show more environmental awareness, but in the other country groups, with higher uncertainty avoidance patterns, this relationship is not visible.

$\square$ The pattern for masculinity is somewhat different. The overall sample shows a negative correlation between the environmental awareness and the level of masculinity, and this regards the Scandinavian countries (with the lowest level of masculinity) and the other Western countries (with the highest level of masculinity), too. However, in the Mediterranean group no such relationship exists, and in the Former socialist countries, the correlation is actually positive. This means that in Scandinavia and in Western Europe, more feminine cultural values empathy, sensitivity, cooperation - bring about more awareness of the environmental problems, while in the Former socialist countries, the more masculine values - i.e. a competitive approach, rationality create the same effect. The Former socialist countries look at the environment as a competitive resource and deal with it accordingly, while the Scandinavian and the other Western countries consider it a resource necessary for a pleasant way of life.

$\square$ Regarding the long-term orientation, we would expect that the higher levels of long-term orientation are associated with the higher environmental awareness, but the pooled sample of all countries shows a very weak negative correlation. Interestingly, the expected positive correlation emerges in the Scandinavian country group and in the other Western country group, but in the other two country groups, the correlation is very weak, however, still positive.

Looking at these rather mixed results, no general pattern seems to emerge. Therefore, the question, whether some other background factor may influence these patterns, arises. The impact of time was also tested on both the environmental awareness and the per capita income.

Regarding income (table 4), only a mild positive correlation can be viewed, but it is present in each of the country groups. The same is true for the environmental awareness, but the positive correlations are much stronger here (only the Mediterranean countries show a low correlation coefficient) - indicating, that the environmental awareness increases everywhere with time.

Due to the mixed character of the correlation coefficients, it is reasonable to assume that the cultural dimensions act not separately, but interplay exists between several of them in influencing the environmental awareness pattern of the EU citizens. Therefore, a multiple regression analysis was performed as the next step to see if there was any significant relationship between the Hofstede dimensions and the environmental awareness of the population. The ENAW variable was taken as the dependent variable, while time, national income level, and the six cultural dimensions were applied as independent variables.

Firstly, the ENAW variable was related to various Hofstede dimensions to see the shape of a possible relationship. Looking at figure 2, in which ENAW is related to INDG, there is an indication of a non-linear relationship. As figure 2 shows, a quadratic relationship gives a better fit. Therefore, in the linear multiple regression model, instead of the original environmental awareness variable, the square root (SqrtENAW) was used as the dependent variable. At first, the model did not include the country groupings, but considered all the countries as one homogeneous sample. Model 1 sums up the results of the fitted model. The left panel of figure 3 shows the observed vs. predicted values of the regression.

As the results show, without segmenting the countries, the year had a definite significant positive impact, which shows the environmental awareness increase with time. GDP_per_cap, PDI and INDI seem to be indifferent. 




Figure 2 The environmental awareness \% vs. Hofstede's Indulgence dimension values Source: author's own research

Significant negative impacts were found for MAS and UNA (at 10\% level), and significant positive relationship with LTO and INDG.

For adding the country groups into the model, three dummy variables had to be added, one for SC, one for FS and one for ME. There is no need for a dummy to identify OW countries, because all the countries outside SC, ME and FS belong there and including a dummy for OW would then result in severe multicollinearity.
Including the variables for these three country groups completely changes the model, as it is shown in table 5 - model 2.

The positive impact of the year and the indifference of GDP_per_cap and PDI remained unchanged, as well as the positive influence of LTO and INDG. However, the significant negative impacts of MAS and UNA disappeared, while a positive influence of INDI emerged, together with a positive influence of the SC dummy. The other two areas remained indifferent.

The adjusted $R^{2}$ increased considerably, and the good fit of the model is shown in the right panel of figure 3 .

The change between the coefficients of Model 1 and Model 2 shows that the formerly negative impacts of masculinity and uncertainty avoidance are changed, due to the Scandinavian country group, and including Scandinavia as a variable makes these factors no longer relevant.

Individuality becomes important. However, as it is a factor, it has a significant influence on all the other country groups, not only on Scandinavia. Therefore, we may conclude, that:

$\square$ The environmental awareness increases everywhere with time.

$\square$ The environmental awareness is higher in more indulgent countries, where the longterm orientation is high. This means that

Table 5 Coefficients and the fit model for the models 1 and 2

\begin{tabular}{|c|c|c|c|c|c|c|c|c|}
\hline \multirow{3}{*}{$\frac{\text { Dependent }}{\text { Coefficients }}$} & \multicolumn{4}{|c|}{ MODEL 1} & \multicolumn{4}{|c|}{ MODEL 2} \\
\hline & \multicolumn{4}{|c|}{ SqrtENAW (all countries) } & \multicolumn{4}{|c|}{ SqrtENAW (with country group dummies) } \\
\hline & B & Beta & $p$ & VIF & B & Beta & $p$ & VIF \\
\hline (Constant) & -487.452 & & .000 & & -512.942 & & .000 & \\
\hline Year & .242 & .354 & .000 & 1.043 & .254 & .375 & .000 & 1.018 \\
\hline GDP_per_cap & $1.259 \mathrm{E}-5$ & .116 & .297 & 5.523 & $-1.978 \mathrm{E}-7$ & -.002 & .976 & 3.547 \\
\hline PDI & .004 & .056 & .428 & 2.236 & .002 & .037 & .556 & 2.292 \\
\hline INDI & .008 & .099 & .164 & 2.270 & .009 & .121 & .057 & 2.323 \\
\hline MAS & -.008 & -.148 & .005 & 1.186 & -.001 & -.010 & .848 & 1.437 \\
\hline UNA & -.007 & -.111 & .093 & 1.940 & .004 & .066 & .350 & 2.893 \\
\hline LTO & .020 & .240 & .000 & 1.485 & .026 & .313 & .000 & 1.798 \\
\hline INDG & .037 & .535 & .000 & 4.198 & .034 & .491 & .000 & 4.218 \\
\hline SC dummy & & & & & 1.741 & .404 & .000 & 2.192 \\
\hline FS dummy & & & & & -.169 & -.061 & .583 & 7.251 \\
\hline ME dummy & & & & & -.209 & -.060 & .419 & 3.186 \\
\hline Adjusted $R^{2}$ & \multicolumn{4}{|c|}{0.597} & \multicolumn{4}{|c|}{0.677} \\
\hline Std. Error of Estimate & \multicolumn{4}{|c|}{0.8699} & \multicolumn{4}{|c|}{0.7711} \\
\hline Regression F $(p<0.001)$ & \multicolumn{4}{|c|}{34.562} & \multicolumn{4}{|c|}{36.817} \\
\hline df (regression; residual) & \multicolumn{4}{|c|}{$8 ; 173$} & \multicolumn{4}{|c|}{$11 ; 177$} \\
\hline
\end{tabular}

B - the unstandardised coefficients, Beta - standardised coefficients, $p$ - error probability of the estimates, VIF - variance inflation factor to test multicollinearity Source: author's own research 

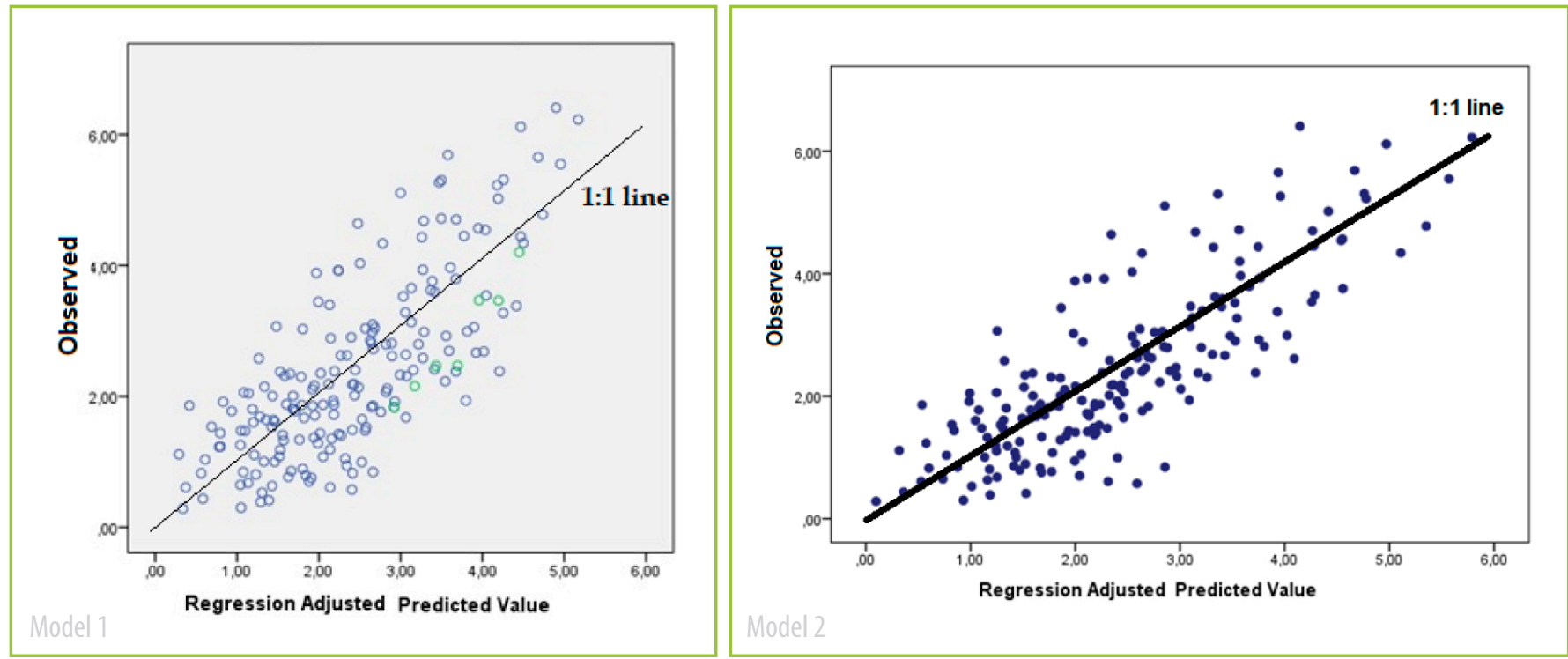

Figure 3 Scatter plots of the observed vs. predicted dependent variables, model 1 and model 2 Source: author's own research

these countries are indulgent, pleasure seeking, but with a concern about sustainability, with an approach of 'enjoy and protect'.

$\square$ In more individualistic cultures, the environmental awareness is higher, as they are more willing to take the personal responsibility for their living standards, instead of waiting for some public action to solve their problems.

$\square$ More long-term oriented societies are more aware of the importance of the environment.

$\square$ Generally, the Scandinavian countries are more sensitive to the environment, probably, due to their more sensitive and more unique natural conditions.

$\square$ Masculinity, or uncertainty avoidance does not matter beyond the listed factors and their impacts may only be felt in the Scandinavian countries, where the levels of these two cultural dimensions are strikingly low.

\section{Conclusions}

The present research focused on identifying a relationship among the national cultural traits and the environmental awareness of population.

Using Hofstede's cultural dimensions and the Eurobarometer survey data about the environmental awareness of the $\mathrm{EU}$ citizens, i.e. the percentage of people who put the environmental issues among the most important concerns of the country, correlation and multiple regression analyses were applied. The analyses were being performed for seven years between 2012 and 2018, having the EU member states (including the UK) as one sample, and also having 4 different country groups classified by their geographical location and recent history.

Results have shown that considerable differences among the groups of the Scandinavian, Mediterranean, other Western and Former socialist countries exist, regarding their environmental awareness, income levels and cultural dimension values. Due to these differences, when the country groups are merged into one group of the EU, some of these differences become invisible and their impacts disappear. However, when the country groups are tested separately, the Scandinavian group comes out as one with rather unique features, the most marked ones being a very low level of masculinity and good tolerance towards uncertainty. The other three country groups did not show such marked difference as far as the environmental awareness was concerned.

The analysis has shown that the environmental awareness of the $E U$ citizens shows an increasing trend with time. It is also higher in the indulgent and pleasure-seeking societies, where the pleasures offered by the natural environment are valued, and therefore, sustainability is taken more seriously. More individualistic countries also show more responsibility towards the environmental issues, and this is quite reasonable. These societies do not expect a paternalistic approach from the state, but they take action and accept the personal responsibility themselves. Not surprisingly, more long-term oriented societies are more aware of the importance of the environment. The other cultural traits - masculinity, uncertainty avoidance and power - did not matter at all anywhere, except for the Scandinavian countries, which considerably differ from the rest of the EU by very low values of these features.

Our findings are partly in line with the findings of the earlier studies about the environmental consciousness and the cultural features. Milfont and Schultz (2016) also found out that the future-thinking orientation is associated with pro-environmentalist behaviour, similarly to our findings about the long-term orientation. They also found out that in the western societies, geography did not change the pro-environmentalist behaviour, which is similar to our findings, concerning only the location in Scandinavia being important from the viewpoint of the environmental awareness. High levels of indulgence and individualism were also found in a different context - as the positive factors in an innovation performance (Andrijauskiene and Dumciuviene, 2017). And seeking the sustainable solutions to the environmental problems really requires innovative approaches. In contrast to our findings of no impact of the power distance and positive impact of individuality, Nagy and Konyha (2018) found out weak negative impacts of the power distance and individuality in $\mathrm{HU}$, in relation to the environmental consciousness. However, they based their research on a within-country analysis of the national cultural traits and therefore, their context is different from our all-European comparisons. Hungary is a country with lower power distance and a higher level of individuality than the average Former socialist countries. Therefore, its performance is not typical for its country group. On the other hand, the differences of the cultural values within a country are 
based on the same national culture and their relative differences may not be comparable with the national average values country-wise. As Cox et al. (2011) pointed out, the directions of correlations among various cultural dimensions may also depend on the actual magnitudes of these dimensions. Therefore, the relationships valid in a narrower range (e.g. within countries or similar country groups) may not be valid for a more extensive and more variable sample.

Limitations of the present research are related to the availability of the Hofstede cultural indicators. Surveys are taken relatively rarely, and the national cultural dimensions are also rarely updated. Although the cultural characteristics are considered relatively stable, with mobility and migration being a general feature of globalisation, more frequent updating of the cultural indicators may show more refined view on their impacts.

\section{Acknowledgement}

The author acknowledges the financial support of Széchenyi 2020 under the EFOP-3.6.1-16-2016-00015 project.

\section{References}

ANDRIJAUSKIENE, M. - DUMCIUVIENE, D. 2017. Hofstede's cultural dimensions and national innovation level. In DIEM: Dubrovnik International Economic Meeting, vol. 3, 2017, no. 1, pp. 189-205.

ANDRIJAUSKIENE, M. - DUMCIUVIENE, D. 2018. National culture as a determinant of firms' innovative performance. In Forum Scientiae Oeconomia, vol. 6, 2018, no.1, pp. 47-68.

BARKLEY, D. L. - EGGERTSSON, M. 2017. Using Hofstede's model to improve multicultural management in the European Union. In Journal of International Management Studies, vol. 17, 2017, pp. 21-34. D0I: 10.18374/JIMS-17-1.2

CHO, Y. - THYROFF, A. - RAPERT M. I. - PARKS, S. - LEE, H. J. 2013. To be or not to be green: Exploring individualism and collectivism as antecedents of environmental behavior. In Journal of Business Research, vol. 66, 2013, no. 8, pp. 1052-1059. D0I: http://dx.doi.org/10.1016/j.jbusres.2012.08.020

CIMPEANU, A. - PIRJU, S. - MIRONOV, G. 2011. Characterization of European Management Perspective Hofstede's Cultural Dimensions Comparative Analysis. In Proceedings for the International Conference Risk in Contemporary Economy, Galati, Romania, "Dunarea de Jos" University of Galati, Faculty of Economics and Business Administration, 2011, pp. 220-224.

COX, P. - FRIEDMANN, B. A. - TRIBUNELLA, T. 2011. Relationships among Cultural Dimensions, National Gross Domestic Product, and Environmental Sustainability. In Journal of Applied Business and Economics, vol. 12, 2011, no. 6, pp. 46-56.

EC (2012-2019). Standard Eurobarometer Surveys No. 77-N. 92. European Commission Public 0pinion. https://ec.europa.eu/commfrontoffice/publicopinion/index.cfm/ Survey/index\#p=1\&instruments=STANDARD. Accessed: 21 Dec 2019.

EUROSTAT. 2019a. Tourism trips of Europeans - Statistics Explained. Tourism statistics Characteristics of Tourism Trips. https://ec.europa.eu/eurostat/statistics-explained/ index.php/Tourism statistics - characteristics of tourism trips. Accessed: 3 Febr 2020.

EUROSTAT. 2019b. GDP per capita data series. https://ec.europa.eu/eurostat/tgm/table.do $\underline{\text { tab }=\text { table\&plugin }=1 \& \text { language }=\text { en } \& p \text { code }=s d g \quad 08 \quad 10}$. Accessed: 3 Febr 2020

GOODERHAM, P. - NORDHAUG, 0. 2002. Are cultural differences in Europe on the Decline? In European Business Forum, vol. 2, 2002, no. 8, pp. 48-53.
GOULD, R. K. - KRYMKOWSKI, D.H. - ARDOIN, N. M. 2018. The importance of culture in predicting environmental behavior in middle school students on Hawai'i Island. In PLoS ONE, vol. 13, 2018, no. 11, article e0207087. https://doi.org/10.1371/journal. pone.0207087

HALKOS, G. E. - TZEREMES, N. G. 2013. National culture and eco-efficiency: an application of conditional partial nonparametric frontiers. In Environmental Economics and Policy Studies, vol. 15, 2013, no. 4, pp. 423-441. https//doi.org/10.1007/s10018013-0066-6

HOFSTEDE INSIGHTS. 2016. https://geerthofstede.com/wp-content/uploads/2016/08/6dimensions-for-website-2015-08-16.xls. Accessed: 3 Febr 2020

HOFSTEDE, G.1980. Culture's Consequences: International Differences in Work Related Values. Sage Publications, Beverly Hills, CA, 1980.

HOFSTEDE, G. 2011. Dimensionalizing Cultures: The Hofstede Model in Context. In Online Readings in Psychology and Culture, vol. 2, 2011, no. 1. https://doi.org/10.9707/2307$\underline{0919.1014}$

HOFSTEDE, G. - HOFSTEDE, G. J. - MINKOV, M. 2010. Cultures and Organizations: Software of the Mind (Rev. $3^{\text {rd }}$ ed.). New York : McGraw-Hill, 2010.

HOUSE, R. J. - HANGES, P. J. - JAVIDAN, M. - DORFMAN, P. W. - GUPTA, V. (ed.). 2004 Culture, Leadership and Organizations: The GLOBE Study of 62 Societies. Thousand Oaks: Sage, 2004.

KAASA, A. - VADI, M. - VARBLANE, U. 2014. Regional cultural differences within European countries: evidence from multi-country surveys. In Management International Review, vol. 54, 2014, pp. 825-852.

KAASA, A. - VADI, M. - VARBLANE, U. 2016. A new dataset of cultural distances for European countries and regions. In Research in International Business and Finance, vol. 37, 2016, pp. 231-241.

MEDINA, V. - DERONDA, A. - ROSS, N. - CURTIN, D. - JIA, F. 2019. Revisiting Environmental Belief and Behavior Among Ethnic Groups in the U.S. In Frontiers in Psychology, vol. 10, 2019. Article 629. doi:10.3389/fpsyg.2019.00629

MENSAH, Y. M. - CHEN, H.Y. 2013. Global Clustering of Countries by Culture - An Extension of the GLOBE Study. https://ssrn.com/abstract = 2189904 or http://dx.doi. org/10.2139/ssrn.2189904

MILFONT, T. L. - SCHULTZ, P. W. 2016. Culture and the natural environment. In Current Opinion in Psychology, vol. 8, 2016, no. April, pp. 194-199. D0l: https://doi. org/10.1016/i.copsyc.2015.09.009

MINKOV, M. 2007. What makes us different and similar: A new interpretation of the World Values Survey and other cross-cultural data. Sofia, Bulgaria : Klasika i Stil, 2007.

NAGY, S. - KONYHA, C. 2018. The Effects of Hofstede's Cultural Dimensions on ProEnvironmental Behaviour: How Culture Influences Environmentally Conscious Behaviour. In 'Club of Economics in Miskolc' TMP, vol.14, 2018, no. 1, pp. 27-36. http://dx.doi.org/10.18096/TMP.2018.01.03

ONCE, S. - ALMAGTOME, A. 2014. The Relationship Between Hofstede's National Culture Values and Corporate Environmental Disclosure: An International Perspective. In Research Journal of Business and Management (RJBM), vol. 1, 2014, no. 3, pp. 279-304.

WHITBURN, J. - LINKLATER, W. - ABRAHAMSE, W. 2020. Meta-analysis of human connection to nature and proenvironmental behavior. In Conservation Biology, vol. 34, 2020, no. 1, pp. 180-193. doi:10.1111/cobi.13381

\section{Contact address}

Zsuzsanna Bacsi, University of Pannonia, Georgikon Faculty, Keszthely, Hungary, H-8360, Keszthely, Deák F u. 16, e-mail: h5519bac@ella.hu 